\title{
Relapse of multiple myeloma presenting with biliary obstruction
}

\author{
Alan Coss MD MRCPI ${ }^{1}$, Chen Zhou MD PhD FRCPC ${ }^{2}$, \\ Michael F Byrne MA MD(Cantab) MRCP FRCPC ${ }^{1}$, Alan A Weiss MD FRCPC ${ }^{1}$
}

\begin{abstract}
A Coss, C Zhou, MF Byrne, AA Weiss. Relapse of multiple myeloma presenting with biliary obstruction. Can J Gastroenterol 2010;24(4):237-238.

Pancreatic infiltration is a rare feature of multiple myeloma. A case of a 74-year-old man presenting with symptomatic biliary obstruction two years after the original diagnosis of myeloma is described. Confirmation of pancreatic infiltration with myeloma cells was performed by endoscopic ultrasound-guided fine-needle aspiration. Biliary stenting was performed at endoscopic retrograde cholangiopancreatography. Resolution of the pancreatic mass and the associated biliary stricture was observed after radiation and chemotherapy.
\end{abstract}

Key Words: Biliary obstruction; Cholangiopancreatography; Endoscopic retrograde; Endoscopic ultrasound; Multiple myeloma; Pancreas

\section{CASE PRESENTATION}

A 74-year-old man was admitted to hospital with jaundice, low back and buttock pain, and increasing leg weakness. The jaundice had developed insidiously, with no associated abdominal pain or fevers. The patient had no history of hepatobiliary or pancreatic disease. Two years previously, he had been diagnosed with immunoglobulin A multiple myeloma (MM), for which he was treated with low-dose melphalan and prednisone, with good response. On examination, he was jaundiced, with a normal temperature, no abdominal tenderness or masses, and no features of chronic liver disease. Neurological examination revealed lower limb signs consistent with spinal cord compression. Initial laboratory results included a serum bilirubin level of $126 \mu \mathrm{mol} / \mathrm{L}$ (normal range $0 \mu \mathrm{mol} / \mathrm{L}$ to $18 \mu \mathrm{mol} / \mathrm{L}$ ), aspartate aminotransferase $348 \mathrm{U} / \mathrm{L}$ (normal $10 \mathrm{U} / \mathrm{L}$ to $38 \mathrm{U} / \mathrm{L}$ ), alanine aminotransferase $597 \mathrm{U} / \mathrm{L}$ (normal $25 \mathrm{U} / \mathrm{L}$ to $80 \mathrm{U} / \mathrm{L}$ ) and alkaline phosphatase $402 \mathrm{U} / \mathrm{L}$ (normal $50 \mathrm{U} / \mathrm{L}$ to $200 \mathrm{U} / \mathrm{L}$ ). Blood tests for liver function performed two weeks before admission were within the normal range. Computed tomography (CT) and magnetic resonance imaging demonstrated an extradural mass in the spinal canal at the lumbar (L)3/L4 level with associated cord compression, as well as severe degenerative spinal stenosis at the L4/L5 and L5/sacral 1 levels. CT also revealed a mass in the head of the pancreas, with dilation of the common bile duct and pancreatic duct (Figure 1A). Small, peripancreatic lymph nodes were seen, but with no evidence of vascular invasion or liver involvement. The patient underwent debulking of the spinal tumour with lumbar laminectomy. Endoscopic retrograde cholangiopancreatography demonstrated a short distal common bile duct stricture with proximal biliary dilation (Figure 1B). A $7 \mathrm{~cm}, 10$ Fr plastic stent (Wilson-Cook Medical Inc, USA) was inserted. On endoscopic ultrasound, a $4 \mathrm{~cm}$ pancreatic mass was identified to be compressing, but not

\section{La récidive d'un myélome multiple se manifestant par une occlusion biliaire}

L'infiltration pancréatique est une rare manifestation du myélome multiple. Le cas d'un homme de 74 ans consultant à cause d'une occlusion biliaire symptomatique deux ans après le diagnostic original est décrit. L'échographie endoscopique par aspiration à l'aiguille a permis de confirmer l'infiltration du pancréas par des cellules myélomateuses. On a procédé à une endoscopie biliaire par cholangiopancréatographie rétrograde endoscopique. Après la radiation et la chimiothérapie, la masse pancréatique et l'étranglement biliaire connexe s'étaient résorbés. obstructing, the superior mesenteric vein. Fine-needle aspiration (22 Fr) of the lesion was performed (Figure 1C). Cytological examination identified numerous scattered plasma cells, along with large, atypical plasmacytoid cells demonstrating positive staining for CD138, negative staining for cytokeratin and leukocyte common antigen (CD45), and exhibiting lambda restriction, consistent with a diagnosis of MM (Figure 1D). Radiation therapy was commenced and targeted the pancreatic and lumbar spine lesions (five fractions), as well as a suspected intracardiac plasmacytoma (10 fractions), followed by bortezomib-based chemotherapy. At endoscopic retrograde cholangiopancreatography three months after initial presentation with jaundice, the stent was removed and resolution of the biliary stricture was confirmed. After a further three months, the patient's condition continued to improve, with a normal serum bilirubin level and no evidence of a residual pancreatic mass on $\mathrm{CT}$.

\section{DISCUSSION}

MM is characterized by neoplastic proliferation of plasma cells producing a monoclonal immunoglobulin. The malignant plasma cells proliferate in the bone marrow, leading to skeletal destruction and fractures, often associated with hypercalcemia, anemia and renal impairment. Extramedullary plasmacytomas arising in the absence of marrow or bone involvement are rare and most commonly develop in the upper respiratory tract, although other organ sites, including the gastrointestinal tract, may also be involved $(1,2)$.

In patients with $\mathrm{MM}$, involvement of the pancreas has been reported in $2.3 \%$ of patients, based on the results of autopsy studies, although clinically significant disease is much rarer (3). Involvement of the pancreatic head with either a solitary plasmacytoma or MM typically presents with jaundice, and may be indistinguishable from other forms of pancreatic neoplasia based

${ }^{1}$ University of British Columbia, Division of Gastroenterology, Vancouver General Hospital; ${ }^{2}$ Department of Pathology, BC Cancer Agency, Vancouver, British Columbia

Correspondence: Dr Alan A Weiss, University of British Columbia, Division of Gastroenterology, 5153-2775 Laurel Street, Vancouver,

British Columbia V52 1M9. Telephone 778-997-9332, fax 604-875-5447, e-mail alan.weiss@vch.ca

Received for publication May 11, 2009. Accepted June 22, 2009 

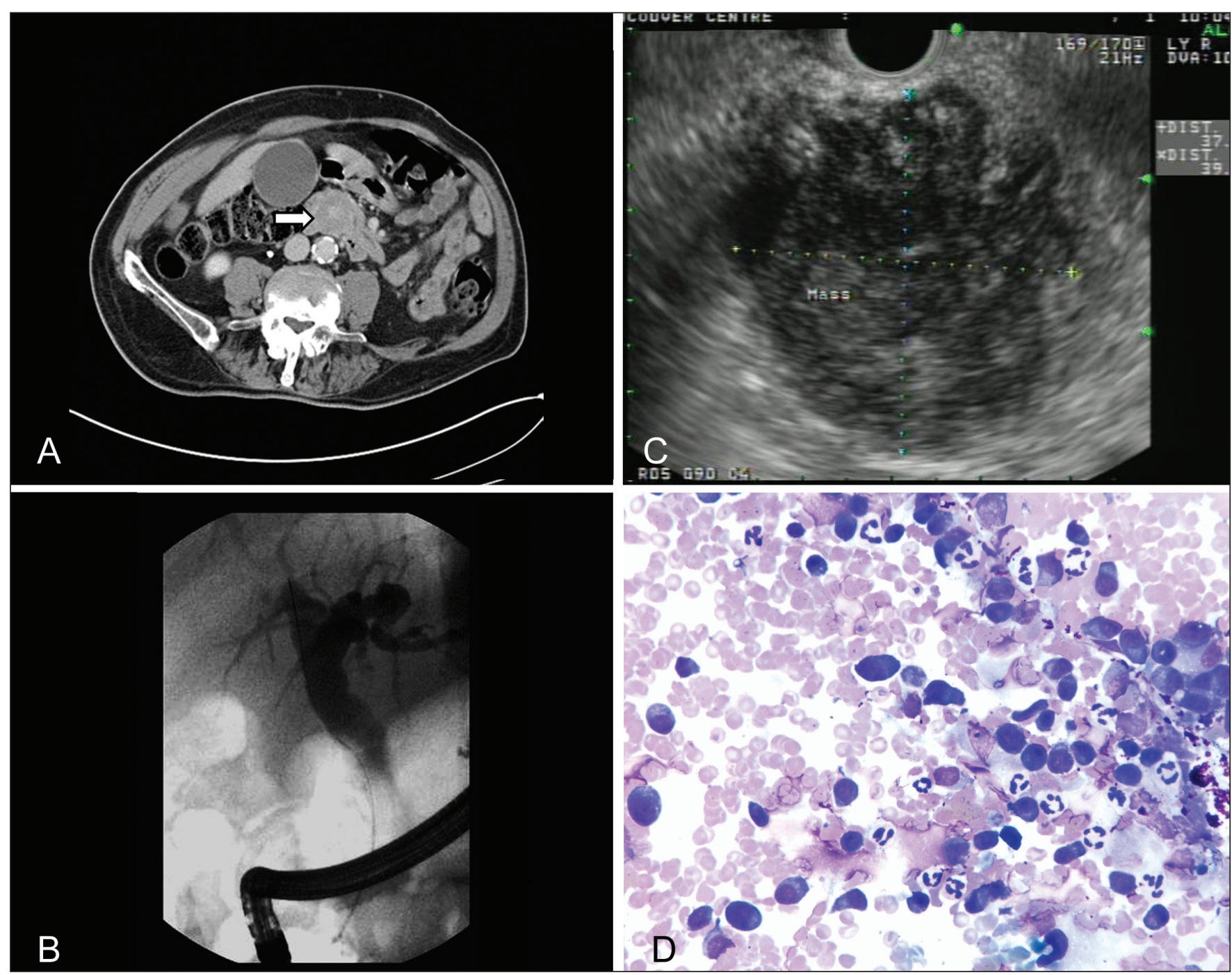

Figure 1) A Computed tomography scan revealing a mass in the region of the head of the pancreas (arrow). B Endoscopic retrograde cholangiopancreatography image demonstrating biliary dilation associated with a long stricture of the distal common bile duct. C Endoscopic ultrasound image revealing a heterogeneous pancreatic mass, measuring $3.9 \mathrm{~cm} \times 3.7 \mathrm{~cm}$. D Fine-needle aspirate of the pancreatic mass demonstrating infiltration with plasma cells (May-Grünwald Giemsa stain, original magnification $\times 40$ )

on radiological appearances alone (4). More diffuse pancreatic involvement or focal disease involving the pancreatic tail have also been reported (5). Confirmation of the diagnosis has traditionally relied on either an operative or CT-guided approach, although more recently, the effectiveness of endoscopic ultrasound-guided fine-needle aspiration of the pancreatic lesion has been reported (6). Extramedullary plasma cell tumours typically respond well to radiation therapy, with a reported median survival of as long as 12 years in those without marrow involvement using this treatment modality alone (2). However, outcomes for those with extramedullary disease associated with MM are considerably poorer, necessitating more aggressive treatment, although radiation therapy may still play an important role.

\section{LESSONS FOR CLINICAL PRACTICE}

- Pancreatic infiltration is a rare feature of MM, with a clinical and radiological presentation that may be indistinguishable from more common forms of cancer.

- Tissue diagnosis may be obtained using endoscopic ultrasound, and is important in guiding treatment, even for those with evidence of extensive disease.

- Although associated with a poor prognosis overall, dramatic local results may be achieved with radiation therapy (often in combination with chemotherapy), leading to resolution of biliary obstruction and reducing the need for repeated biliary stenting procedures.

\section{REFERENCES}

1. Damaj G, Mohty M, Vey N, et al. Features of extramedullary and extraosseous multiple myeloma: A report of 19 patients from a single center. Eur J Haematol 2004;73:402-6.

2. Alexiou C, Kau RJ, Dietzfelbinger H, et al. Extramedullary plasmacytoma: Tumor occurrence and therapeutic concepts. Cancer 1999;85:2305-14.

3. Abu-Hammour AM, Venu RP, Etzkorn KP, et al. Common bile duct obstruction caused by multiple myeloma of the pancreas. Gastrointest Endosc 1996;44:606-8.

4. Hiller N, Goitein O, Ashkenazi YJ. Plasmacytoma of the pancreas. Isr Med Assoc J 2004;6:704-5.

5. Wilson TE, Korobkin M, Francis IR. Pancreatic plasmacytoma: CT findings. AJR Am J Roentgenol 1989;152:1227-8.

6. Spiegel A, Patel R, Pais S. Obstructive jaundice secondary to a pancreatic plasmacytoma. Clin Gastroenterol Hepatol 2009;7:A32. 


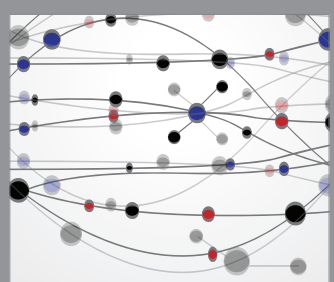

The Scientific World Journal
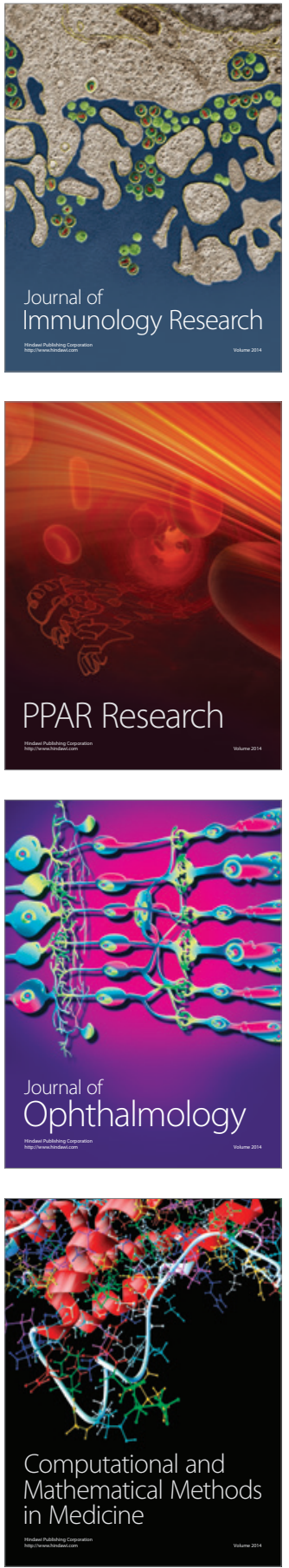

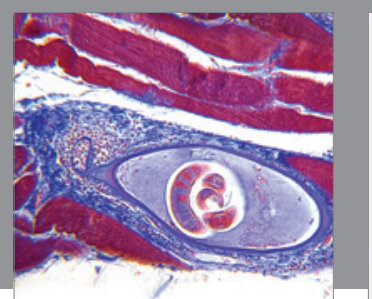

Gastroenterology Research and Practice

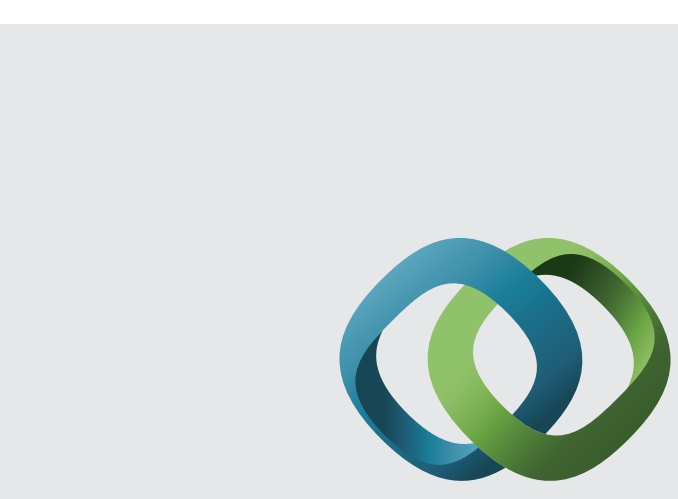

\section{Hindawi}

Submit your manuscripts at

http://www.hindawi.com
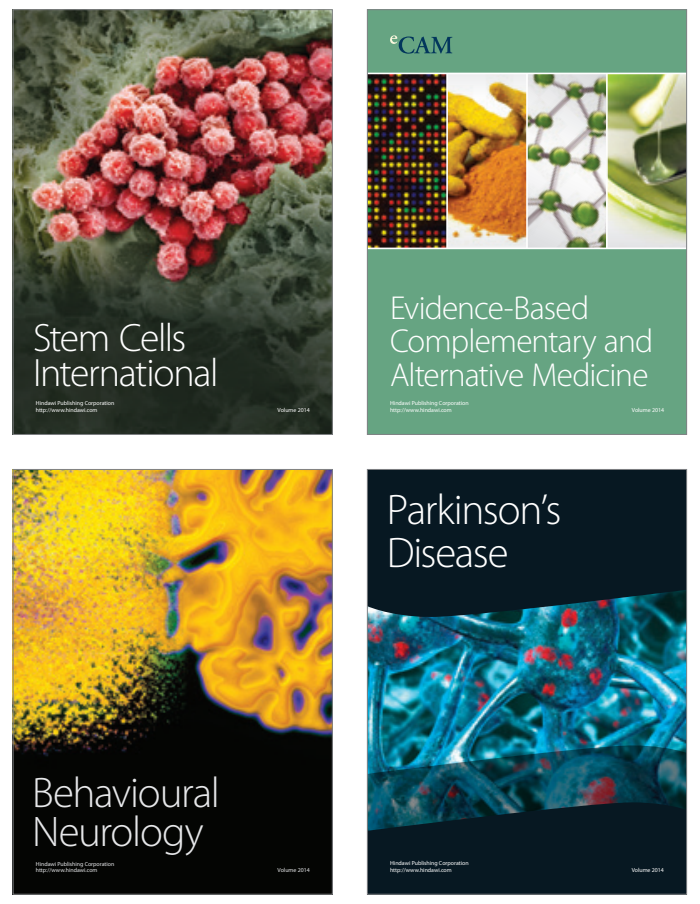
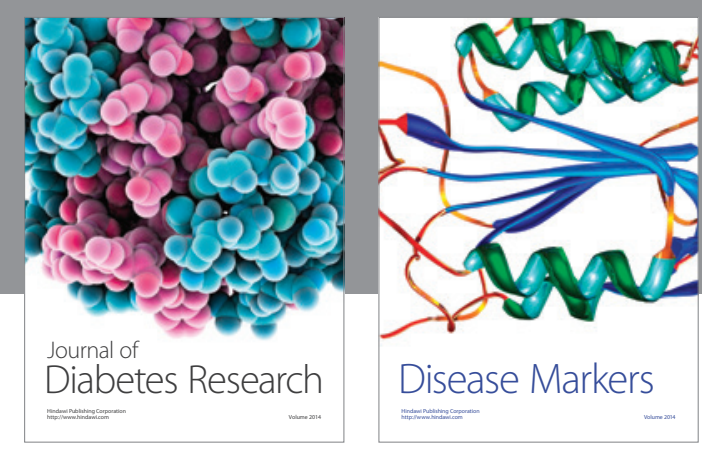

Disease Markers
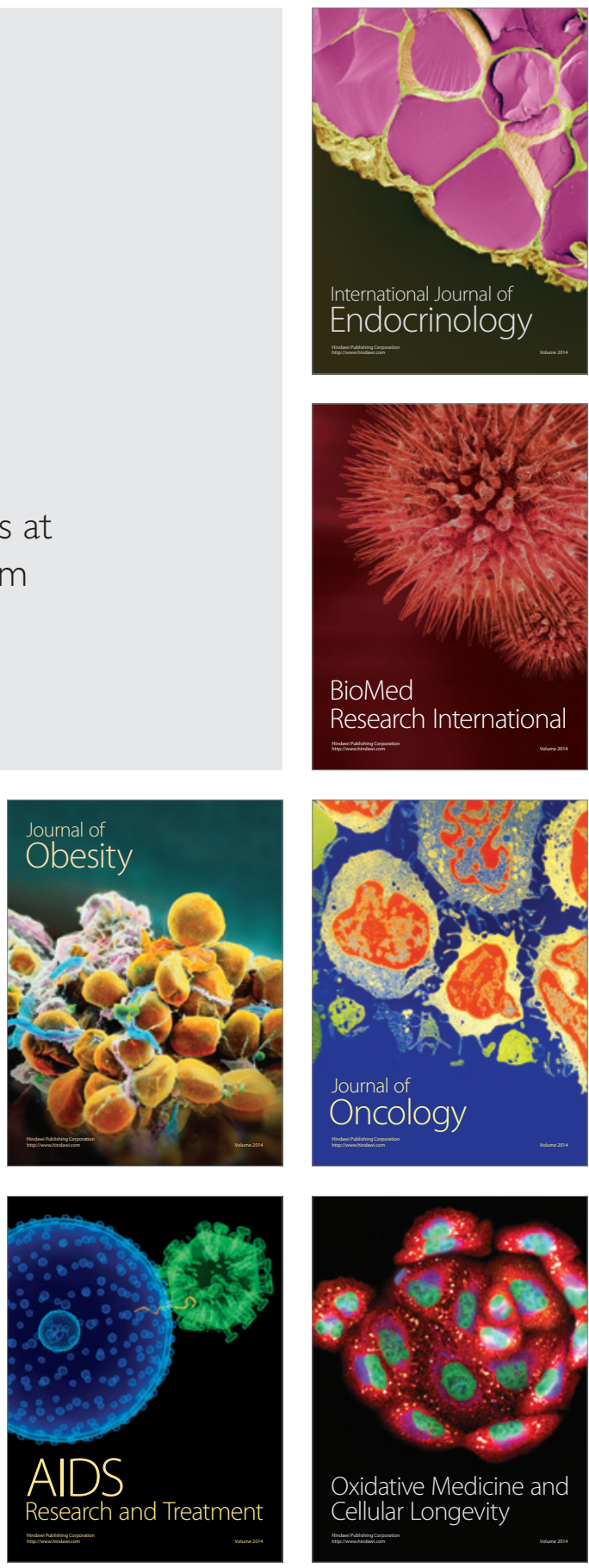